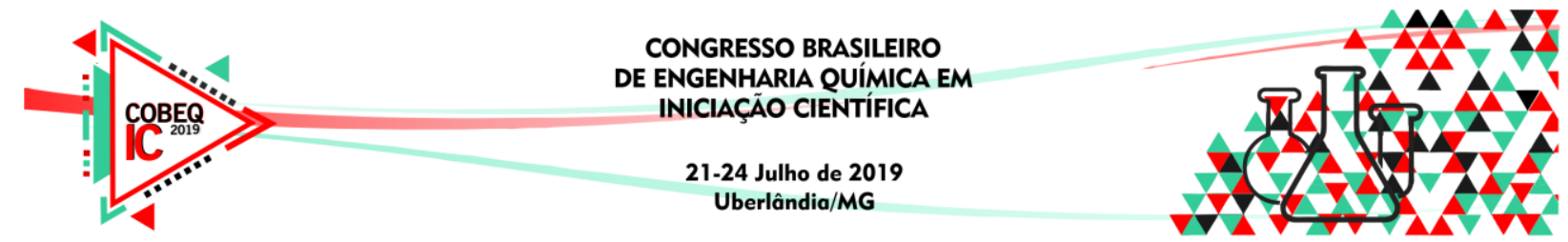

\title{
MODELAGEM E SIMULAÇÃO DA PRODUÇÃO DE BIOGÁS A PARTIR DA VINHAÇA DE UMA DESTILARIA DE ETANOL
}

\author{
C. F. CARNIATO, G. F. LOPES, L. M. M. JORGE E P. R. PARAÍSO \\ Universidade Estadual de Maringá, Departamento de Engenharia Química \\ E-mail para contato: carniatocaio@gmail.com; prparaiso@uem.br
}

\begin{abstract}
RESUMO - A produção de etanol é uma das atividades econômicas mais importantes para o Brasil, e sua produção vem apresentando um grande aumento nos últimos anos. Juntamente com o aumento da produção de etanol ocorre o aumento da produção de vinhaça, resíduo preocupante devido a sua grande produção e potencial poluidor. Entre as opções de tratamento para a vinhaça, há a biodigestão anaeróbica, com a qual é possível realizar a produção do biogás, um gás combustível versátil. Este trabalho apresenta a modelagem da produção de biogás a partir da vinhaça proveniente da destilação do etanol utilizando o software Aspen HYSYS. O modelo utilizado mostrou-se viável do ponto de vista técnico, produzindo $24.645,3 \mathrm{Kg} / \mathrm{h}$ de biogás e composição de acordo com a trazida pela literatura com relação a metano, dióxido de carbono e água.
\end{abstract}

\section{INTRODUÇÃO}

Segundo dados da Conab. (2019), a agroindústria sucroalcooleira mostra-se cada vez mais promissora devido ao elevado preço do petróleo e do esgotamento de suas jazidas. Além disso por ser proveniente de uma fonte renovável e não afetar a camada de ozônio, o etanol é considerado um combustível ecologicamente correto.

A vinhaça produzida com a fermentação da cana-de-açúcar, é considerada o principal resíduo da produção de etanol, não somente pelo grande volume produzido (sendo para cada 1000 toneladas de cana processada, são produzidos $360 \mathrm{~m}^{3}$ de vinhaça), mas principalmente devido ao alto potencial poluidor (Theodoro, 2005).

Neste cenário, a biodigestão anaeróbia da vinhaça surge como uma alternativa de tratamento deste subproduto apresentado, ainda, uma importante consequência econômica: a produção de biogás e seu aproveitamento como fonte de energia (Corazza, 1996).

De acordo com Labriet et al. (2013), o biogás pode ser usado diretamente, purificado e utilizado ou ainda purificado e armazenado para posterior utilização. Assim, pode ser utilizado em: aplicações domésticas para aquecimento e iluminação; produção de energia elétrica e calor, ou injeção na rede elétrica; e como combustível automotivo, após transformar o biogás em biometano. 


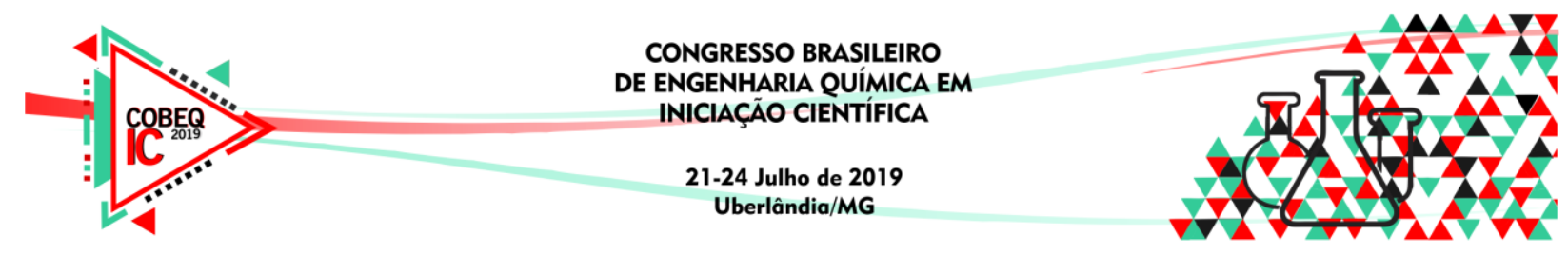

Sendo assim, esse projeto tem como objetivo realizar a modelagem da produção do biogás através da biodigestão anaeróbica da vinhaça, utilizando o software Aspen HYSYS, verificando-se a quantidade produzida e sua composição comparada à literatura.

\section{METODOLOGIA}

O modelo proposto é composto por dois reatores de Gibbs,sendo o primeiro utilizado para as reações de hidrolise e acetogeênese e o segundo para as reações de acidogênese e metanogênse, no qual ocorre a síntese direta do biogás. Para realizar a simulação utilizou-se o software Aspen Hysys v9.0, com o modelo termodinâmico NRTL com base no trabalho de Serrano, R. P. (2011).

A entrada da simulação é a vinhaça, cuja a vazão de $83.294 \mathrm{Kg} / \mathrm{h}$ conforme a utilizada no trabalho de Silva et al. (2017), sendo alimentada com $1200 \mathrm{Kpa}$ e $315,15 \mathrm{~K}$ com base nos trabalhos de Rohstoffe, F. N. (2010) e Serrano, R. P. (2011) respectivamente.

A composição geral da vinhaça, foi baseada nos trabalhos de Michael et al. (1994), apresentando sua versão resumida na Tabela 1.

Tabela 1 - Composição da vinhaça

\begin{tabular}{|c|c|}
\hline Composto & Concentração (g/L) \\
\hline \hline Acetaldeido & 0,697 \\
\hline Etanol & 3,83 \\
\hline Propilenoglicol & 0,0084 \\
\hline Butano-2,3-diol & 0,568 \\
\hline Glicerol & 5,86 \\
\hline Eritritol & 0,088 \\
\hline Arabinitol & 0,064 \\
\hline Manitol & 0,089 \\
\hline Chiro-inositol & 0,114 \\
\hline Myo-isonitol & 0,236 \\
\hline Sacarose & 0,222 \\
\hline Ácido acético & 1,56 \\
\hline Ácido fórmico & 0,582 \\
\hline Ácido lático & 7,74 \\
\hline Ácido quínico & 0,508 \\
\hline Fonte: Ádaptada de Michael
\end{tabular}

Fonte: Adaptada de Michael et al., 1994.

A fim de se obter uma simplificação para modelagem, utilizou-se como composição da vinhaça para a simulação do processo de biodigestão anaeróbica, os compostos em maior quantidade e maior importância para a composição final do biogás. Baseando-se na Tabela 1 (Michael et al., 1994), adotando a vinhaça concentrada a 33\% de água baseada nas reações utilizdas, definiu-se a composição de entrada da simulação como mostra a Tabela 2. 
Tabela 2 - Composição da vinhaça utilizada na modelagem.

\begin{tabular}{|c|c|}
\hline Composto & Fração mássica \\
\hline \hline Etanol & 0,4132 \\
\hline Ácido acético & 0,1683 \\
\hline Butano-2,3-diol & 0,0613 \\
\hline Sacarose & 0,0239 \\
\hline Água & 0,3333 \\
\hline
\end{tabular}

Dessa forma as principais reações que ocorrem durante a biodigestão anaeróbica, com base no trabalho de Moraes et al. (2015) são as seguintes:

Hidrólise:

$\mathrm{C}_{12} \mathrm{H}_{22} \mathrm{O}_{11}+\mathrm{H}_{2} \mathrm{O} \rightarrow 2 \mathrm{C}_{6} \mathrm{H}_{12} \mathrm{O}_{6}$

Acidogênese:

$\mathrm{C}_{6} \mathrm{H}_{12} \mathrm{O}_{6}+2 \mathrm{H}_{2} \mathrm{O} \rightarrow 2 \mathrm{CH}_{3} \mathrm{COO}^{-}+2 \mathrm{CO}_{2}+2 \mathrm{H}^{+}+4 \mathrm{H}_{2}$

$\mathrm{C}_{6} \mathrm{H}_{12} \mathrm{O}_{6}+2 \mathrm{H}_{2} \rightarrow 2 \mathrm{CH}_{3} \mathrm{CH}_{2} \mathrm{COO}^{-}+2 \mathrm{H}_{2} \mathrm{O}+2 \mathrm{H}^{+}$

$\mathrm{C}_{6} \mathrm{H}_{12} \mathrm{O}_{6} \rightarrow \mathrm{CH}_{3} \mathrm{CH}_{2} \mathrm{CH}_{2} \mathrm{COO}^{-}+2 \mathrm{CO}_{2}+\mathrm{H}^{+}+2 \mathrm{H}_{2}$

Acetogênese:

$\mathrm{CH}_{3} \mathrm{CH}_{2} \mathrm{COO}^{-}+3 \mathrm{H}_{2} \mathrm{O} \rightarrow \mathrm{CH}_{3} \mathrm{COO}^{-}+\mathrm{HCO}_{3}^{-}+\mathrm{H}^{+} 3 \mathrm{H}_{2}$

$\mathrm{CH}_{3} \mathrm{CH}_{2} \mathrm{COO}^{-}+2 \mathrm{HCO}_{3}^{-} \rightarrow \mathrm{CH}_{3} \mathrm{COO}^{-}+\mathrm{H}^{+}+3 \mathrm{HCOO}^{-}$

$\mathrm{CH} 3 \mathrm{CH}_{2} \mathrm{CH}_{2} \mathrm{COO}^{-}+2 \mathrm{H}_{2} \mathrm{O} \rightarrow 2 \mathrm{CH}_{3} \mathrm{COO}^{-}+\mathrm{H}^{+}+2 \mathrm{H}_{2}$

Metanogênese:

$\mathrm{CH}_{3} \mathrm{COO}^{-}+\mathrm{H}_{2} \mathrm{O} \rightarrow \mathrm{CH}_{4}+\mathrm{HCO}_{3}^{-}+2 \mathrm{H}_{2}$

$\mathrm{H}_{2}+1 / 4 \mathrm{HCO}_{3}{ }^{-}+1 / 4 \mathrm{H}^{+} \rightarrow 1 / 4 \mathrm{CH}_{4}+3 / 4 \mathrm{H}_{2} \mathrm{O}$

$\mathrm{HCOO}^{-}+1 / 4 \mathrm{H}_{2} \mathrm{O}+1 / 4 \mathrm{H}^{+} \rightarrow 1 / 4 \mathrm{CH}_{4}+3 / 4 \mathrm{HCO}_{3}^{-}$

A partir dessas reações foram geradas as seguintes reações globais.

$$
\begin{aligned}
& \mathrm{C}_{12} \mathrm{H}_{22} \mathrm{O}_{11}+\mathrm{C} 6 \mathrm{H} 12 \mathrm{O} 6+\mathrm{H}_{2} \mathrm{O} \rightarrow 2 \mathrm{C}_{2} \mathrm{H}_{4} \mathrm{O}_{2}+2 \mathrm{C}_{3} \mathrm{H}_{6} \mathrm{O}_{2}+\mathrm{C}_{4} \mathrm{H}_{8} \mathrm{O}_{2}+4 \mathrm{CO}_{2}+4 \mathrm{H}_{2} \\
& 2 \mathrm{C}_{3} \mathrm{H}_{6} \mathrm{O}_{2}+\mathrm{C}_{4} \mathrm{H}_{8} \mathrm{O}_{2}+\mathrm{H}_{2} \mathrm{CO}_{2}+2 \mathrm{H}_{2} \mathrm{O} \rightarrow 3 \mathrm{C}_{2} \mathrm{H}_{4} \mathrm{O}_{2}+\mathrm{H}_{2}+3 \mathrm{CH}_{4}+2 \mathrm{CO}_{2}
\end{aligned}
$$




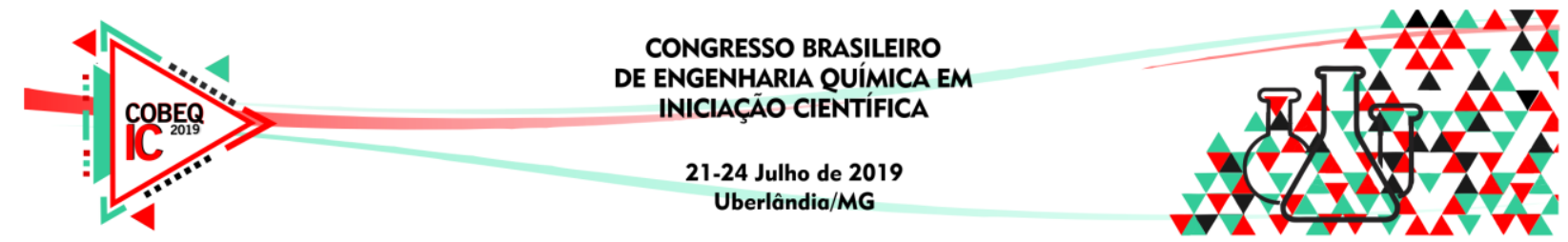

Sendo a reações (11) englobando as etapas de hidrólise e acidogênese, acoplada ao primeiro reator e a reação (12) englobando as etapas de acetogênese e metanogênese, acoplada ao segundo reator.

\section{RESULTADOS E ANÁLISE}

A Figura 1, em seguida, traz o modelo obtido no Aspen HYSYS para simulação da biodigestão aneróbia da vinhaça para produção de biogás.

Figura 1 - Modelo da biodigestão anaeróbia da vinhaça.

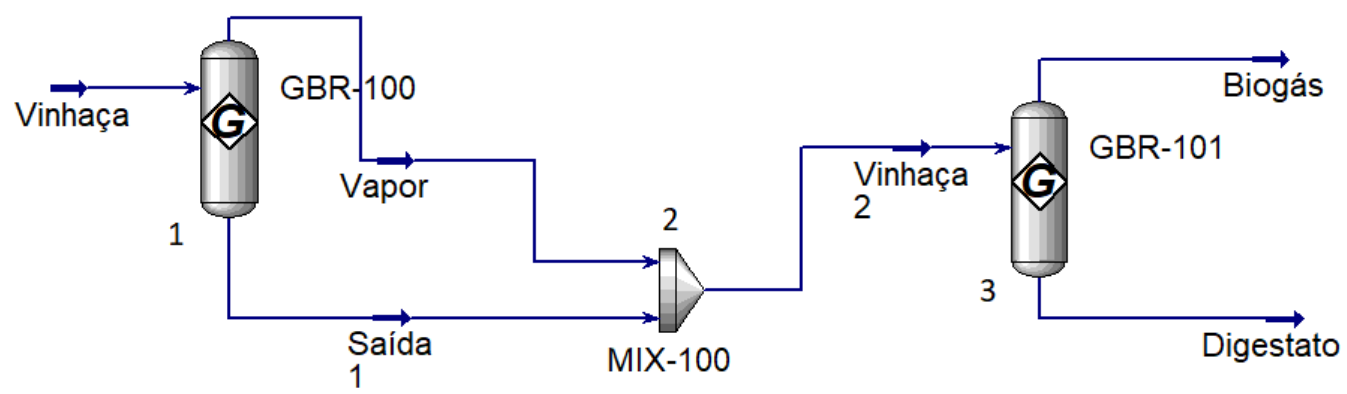

Com a simulação realizada por esse modelo, obteve-se uma produção de $24.645,3 \mathrm{Kg} / \mathrm{h}$ de biogás, composto de 50,36\% de metano e $29,8 \%$ de dióxido de carbono em volume. $\mathrm{O}$ modelo apresentou uma produção de $61,95 \%$ da vazão mássica esperada de acordo com o trabalho de Silva et al. (2017), cuja produção considerada foi de $39.790 \mathrm{Kg} / \mathrm{h}$ de biogás.

Através da Tabela 3 é possível comparar a composição de biogás obtida utilizando o modelo proposto, com a composição apresentada por Labriet et al. (2013).

Tabela 3 - Análise da composição do biogás obtido

\begin{tabular}{|c|c|c|}
\hline Composto & Modelagem & Literatura \\
\hline \hline Etanol & 0,0553 & - \\
\hline Dióxido de carbono & 0,298 & $0,25-0,45$ \\
\hline Água & 0,0113 & $0,01-0,05$ \\
\hline Metano & 0,5036 & $0,5-0,7$ \\
\hline
\end{tabular}

A partir dos dados da Tabela 3, observa-se que o biogás produzido pelo modelo simulado tem composição de acordo com a literatura, segundo Labriet et al. (2013), demonstrando a viabilidade técnica do modelo.

\section{CONCLUSÃO}

Com o modelo proposto, simulou-se, portanto A biodigestão anaeróbia da vinhaça para a produção de biogás. O modelo apresentou uma produção de $24.645,3 \mathrm{Kg} / \mathrm{h}$ de biogás - 


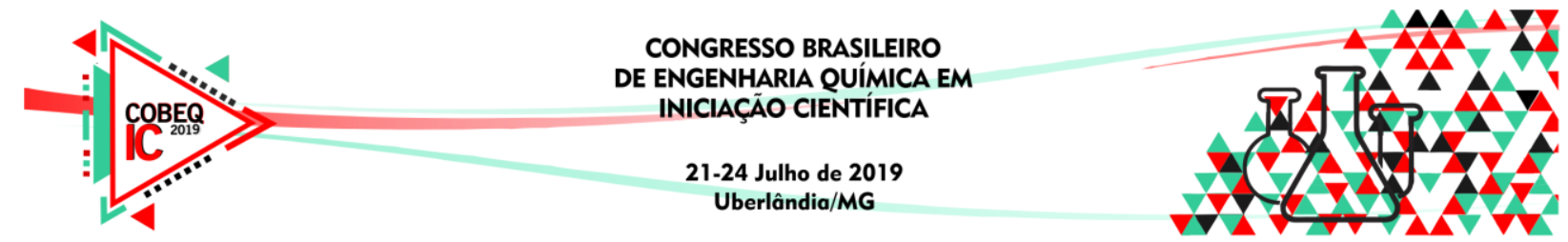

61,95\% da vazão mássica esperada segundo Silva et al. (2017) - e uma composição de metano, dióxido de carbono e água dentro dos valores propostos por Labriet et al. (2013), demosntrando sua viabilidade do ponto de vista técnico.

\section{REFERÊNCIAS BIBLIOGRÁFICAS}

CONAB - Companhia Nacional de Abastecimento. Acomp. safra bras. cana, v. 5 - Safra 2018/19, n. 4 - Quarto levantamento, p. 1-75, 2019.

CORRAZA, R. I. Reflexões sobre o papel das políticas ambientais e de ciência e tecnologia na modelagem de opções produtivas "mais limpas" numa perspectiva evolucionista: um estudo sobre o problema da disposição da vinhaça. Universidade Estadual de Campinas, Campinas, 1996.

LABRIET, M.; SIMBOLOTTI, G.; TOSATO, G. Biogas and Bio-syngas Production. ETSAP - Energy Technology System Analysis Programme, 2013.

MICHAEL, K. D.; STEVE, L. J.; LAURA, C.; PETER, J. R. Low Molecular Weight Organic Composition of Ethanol Stillage from Sugarcane Molasses, Citrus Waste, and Sweet Whey. J. Agric. Food Chem, v. 42 , p. 283-288, 1994.

MORAES, B. S.; ZAIAT, M.; BONOMI, A. Anaerobic digestion of vinasse from sugarcane ethanol production in Brazil: Challenges and perspectives. Renewable and Sustainable energy reviews, v. 44, p. 888-903, 2015.

ROHSTOFFE, F. N. Guia Prático do Biogás: Geração e Utilização. Ministério da Nutrição, Agricultura e Defesa do Consumidor da Alemanha, 2010.

SERRANO, R. P. Biogas Process Simulation using Aspen Plus. Departament of Chemical Engineering. Syddansk Universitet, 2011.

SILVA, R. O,; YOSHI, H. C. M. H.; ROCHA, L. B.; LIMA, O. C. M.; JIMÉNEZ, L.; JORGE, L. M. M. Synthesis of a New Route for Methanol Production by Syngas Arising from Sugarcane Vinasse, Computer Aided Chemical Engineering, v. 40, p 811816, 2017.

THEODORO, J. M. P. Considerações sobre os custos ambientais decorrentes do gerenciamento dos resíduos sólidos e efluentes industriais gerados no setor sucroalcooleiro: um estudo de caso. Centro Universitário de Araraquara, Araraquara, 2005. 